\title{
SISTEM PENDUKUNG KEPUTUSAN PENENTUAN DOSEN TERBAIK MENGGUNAKAN METODE ANALYTICAL HIERARCHY PROCESS (AHP) PADA STMIK PRIMAKARA
}

\author{
I Wayan Sutrisna Yasa ${ }^{1}$, Komang Tri Werthi ${ }^{2}$, I Putu Satwika ${ }^{3}$ \\ ${ }^{1,3}$ Program Studi Teknik Informatika \\ ${ }^{2}$ Program Studi Sistem Informasi Akutansi \\ STMIK Primakara \\ Denpasar, Indonesia

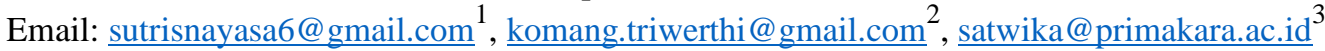

\begin{abstract}
Penelitian ini membahas mengenai penerapan metode Analytical Hierarchy Process (AHP) sebagai sistem pendukung keputusan dengan studi kasus menentukan dosen terbaik. Selain itu dalam penelitian ini juga dilakukan perhitungan terhadap nilai konsistensi rasio dengan menggunakan beberapa nilai indeks random yang telah ditemukan oleh para peneliti. Nilai indeks random yang digunakan dalam penelitian ini meliputi nilai indeks random dari Saaty, Noble, Oak Ridge, Golden Wang, Tumala Wan, Aguaron, dan Alonso Lamata. Dalam kasus ini terdapat empat kriteria yang digunakan yaitu Pendidikan, Penelitian, Pengabdian Masyarakat, dan Penunjang. Masing - masing kriteria memiliki bobot awal yaitu Pendidikan 40\%, Penelitian 25\%, Pengabdian Masyarakat 25\% dan Penunjang 10\%. Penelitian dilakukan di kampus STMIK Primakara, Jalan Tukad Badung No. 135 Renon, Denpasar Bali. Tujuan dari penelitian ini yaitu melakukan perhitungan menggunakan metode Analytical Hierarchy Process (AHP) dan juga mengukur berapa nilai konsistensi rasio yang dihasilkan dengan menggunakan nilai indeks random dari Saaty, Noble, Oak Ridge, Golden Wang, Tumala Wan, Aguaron, dan Alonso Lamata dalam penentuan dosen terbaik. Sehingga, hasil dari penelitian ini berupa perangkingan dosen terbaik dan juga seberapa besar nilai konsistensi keputusan yang didapatkan berdasarkan hasil perhitungan konsistensi rasio dari metode Analytical Hierarchy Process dengan menggunakan nilai indeks random dari beberapa peneliti.
\end{abstract}

Keywords - Sistem Pendukung Keputusan, Analytical Hierarchy Process, Dosen Terbaik, STMIK Primakara.

\section{PENDAHULUAN}

Dosen memegang peranan yang cukup penting dalam perguruan terutama dalam proses pendidikan dan permbelajaran. Menurut Undang - Undang No 14 tahun 2005 pasal 51 ayat 1 butir b dinyatakan bahwa dosen berhak meperoleh penghargaan atas kinerjanya selama diperguruan tinggi[1]. Disisi lain teknologi informasi terus berkembang dengan pesat, salah satu dari perkembangan teknologi informasi adalah munculnya sistem pendukung keputusan. Sistem pendukung keputusan merupakan sebuah sistem yang membantu pengambil keputusan dalam mengambil sebuah keputusan[2]. Terdapat banyak metode atau algoritma yang dapat digunakan dalam sistem pendukung keputusan, antara lain metode Weighted Product (WP), TOPSIS, Simple Addictive Weighting (SAW), Analytical Hierarchy Process (AHP) dan lain - lain[3].

Metode Analytical Hierarchy Process (AHP) merupakan salah satu metode yang sudah banyak digunakan dalam sistem pendukung keputusan. Metode ini memiliki kemampuan untuk mengukur tingkat konsistensi dari keputusan yang akan dibuat. Salah satu perhitungan konsistensi yang dilakukan dalam metode AHP adalah perhitungan konsistensi rasio, dimana dalam perhitungan ini dilakukan dengan menggunakan nilai indeks random (IR). Seiring berjalannya waktu banyak peneliti yang sudah melakukan penelitian mengenai nilai indeks random Analytical Hierarchy Process, sehingga banyak ada nilai indeks random baru selain indeks random AHP yang ditemukan oleh Saaty. Nilai indeks random yang ditemukan setelah Saaty antara lain nilai indeks random dari penelitian Noble, Oak Ridge, Golden Wang, Tumala Wan, Aguaron, dan Alonso Lamata dan lain - lain[4].

Metode analytical hierarchy process, sudah cukup banyak diterapkan dalam beberapa kasus, misalnya Berdasarkan penelitian yang berjudul "Penilaian Kinerja Dosen dengan menggunakan metode AHP studi kasus di STIE Ahmad 
e-ISSN: 2685-7006 | p-ISSN: 2252-9063

Kumpulan Artikel Mahasiswa Pendidikan Teknik Informatika

(KARMAPATI)

Volume 10, Nomor 3,Tahun 2021

\section{KดRMAPดTI}

Dahlan Jakarta" yang dilakukan oleh Didik Setiyadi pada tahun 2012 menggunakan metode AHP dengan indeks random Saaty hasilnya berupa perhitungan dari data seluruh responden yaitu dengan nilai ketidak konsistenan kurang dari $10 \%$ sehingga hasilnya akurat[5].

Kemudian penelitian dengan judul "Sistem Pendukung Keputusan Penilaian Kinerja Dosen Menggunakan Metode AHP di STIMIK Sepuluh Nopember Jayapura" penelitian dilakukan pada tahun 2018 oleh Patmawati Hasan, Ema Utami, dan Asro Nasiri. Penelitian ini menggunakan metode AHP dan indeks random punyanya Saaty, dimana didapatkan hasil penelitian yaitu, Sistem Pendukung Keputusan Penilaian Kinerja dosen, menggunakan metode Analytical Hierarchy Process (AHP) telah berhasil dibuat dan mampu melakukan penilaian terhadap Dosen di STIMIK Sepuluh Nopember Jayapura berdasarkan aspek Tri Dharma Perguruan Tinggi[6].

Selain itu pada penelitian dengan judul "Sistem Pendukung Keputusan Penilaian Kinerja Dosen Berbasis Fuzzy - AHP Pada Stmik Stikom Bali” yang dilakukan pada tahun 2013 oleh Hary Budiarto dan Indrianto, menggunakan metode fuzzy ahp dengan hasil yaitu berupa prototype dari sistem menggunakan metode Fuzzy - AHP[7].

Kemudian pada penelitian yang berjudul "Sistem Pendukung Keputusan Monitoring \& Evaluasi Kinerja Dosen Program Studi Informatika Fakultas Ilmu Komputer Ibi Kosgoro 1957 Menggunakan Metode Analythic Hierarchy Process (AHP)" yang dilakukan pada tahun 2020 diteliti oleh Boy Firmansyah dan Asep Mulyana Wihandar, menggunakan metode AHP, menghasilkan sistem yang mampu membantu penilaian dosen berprestasi pada Institut Bisnis dan Informasi Kosgoro 1957 (IBI)[8].

Berdasarkan beberapa penelitian yang dijabarkan diatas, dalam implementasi metode analytical hierarchy process, perhitungan konsistensi rasio masih mengandalkan nilai indeks random bawaan yang ditemukan oleh Thomas L.Saaty. sedangkan sudah cukup banyak nilai indeks random yang ditemukan oleh peneliti lain dengan jumlah dimensi matrik yang berbeda atau dengan dimensi yang lebih besar. Indeks random yang ditemukan oleh peneliti lain juga memiliki nilai yang berbeda - beda, sehingga dapat dijadikan alternatif lain dalam perhitungan nilai konsistensi rasio dalam metode analytical hierarchy process.

Sekolah Tinggi Manajemen Informatika dan Komputer (STMIK) Primakara merupakan sebuah perguruan tinggi yang berada di Jalan Tukad Badung No. 135 Renon, Denpasar, Bali. Kampus STMIK Primakara juga sudah melakukan penilaian dan pemberian penghargaan dosen terbaik kepada para dosennya. Dengan menggunakan kriteria penilaian yaitu pendidikan, penelitian, pengabdian masyarakat, dan kegiatan penunjang.

Berdasarkan uraian diatas, maka pada penelitian ini peneliti akan membahas mengenai penerapan metode analytical hierarchy process AHP sebagai sistem pendukung keputusan dalam menentukan dosen terbaik berdasarkan kriteria penilaian dosen terbaik pada STMIK Primakara dan juga melakukan perhitungan mengenai nilai Konsistensi Rasio (CR) dalam metode AHP dengan menggunakan Indeks random yang sudah ditemukan oleh beberapa peneliti, nilai indeks random tersebut meliputi Saaty, Noble, Oak Ridge, Golden Wang, Tumala Wan, Aguaron, dan Alonso Lamata untuk dapat mengetahui apakah nilai indeks random yang ditemukan oleh peneliti lain bisa digunakan dan menghasilkan keputusan dengan konsistensi rasio dibawah 0.1 atau tidak, dengan menggunakan kasus penentuan dosen terbaik. Selain itu juga untuk melihat seberapa besar perbedaan konsistensi rasio yang dihasilkan oleh masing - masing nilai indeks random yang ada.

\section{TINJAUAN PUSTAKA}

\section{A. Dosen Terbaik}

Dosen terbaik merupakan sebuah penghargaan yang diberikan kepada dosen atas prestasinya selama menjalankan tugas sebagai tenaga pendidik. Menurut Undang - Undang Republik Indonesia No 14 tahun 2005 tentang guru dan dosen, Pasal 51 ayat (1) butir b, dinyatakan bahwa setiap dosen mempunyai hak untuk mendapatkan promosi maupun penghargaan atas kinerja akademiknya[1]. Pemilihan dosen terbaik berdasarkan beberapa kriteria penilaian yaitu, karya prestasi unggul yang dapat berupa karya ilmiah atau karya seni, kemudian berdasarkan Tri Darma Perguruan Tinggi yang meliputi, pendidikan dan pembelajaran, penelitian, pengabdian kepada masyarakat, dan kegiatan penunjang. Tujuan dari pemberian penghargaan sebagai dosen terbaik adalah sebagai pengkuan kepada dosen karena telah dapat menjalankan Tri Darma Perguruan Tinggi, dan juga sebagai bentuk aspirasi dan motivasi kepada dosen untuk meningkatkan prestasinya agar terus lebih baik lagi kedepannya[1]

\section{B. Sistem Pendukung Keputusan}

Pada awal tahun 1960-an Michael S.Scot Morton dan G.Antony Gorry mengemukakan sebuah sistem yang diberi nama Management Decision System. Kemudian pada tahun 1971 mulai dikenal dengan istilah Decision Support System (DSS) atau Sistem Pendukung Keputusan (SPK). Sistem Pendukung Keputusan merupakan sebuah sistem berbasis komputer yang memanfaatkan data maupun model tertentu dengan tujuan membantu pengambil keputusan untuk memecahkan permasalahan dalam menentukan dan mengambil keputusan yang sesuai[2]

\section{Analytical Hierarchy Process (AHP)}

Analytical Hierarchy Process (AHP) adalah salah satu metode sistem pendukung keputusan yang dikembangkan oleh Thomas L.Saaty pada tahun 1993. Metode AHP memecahkan permasalahan tidak terstruktur atau semi terstruktur menjadi lebih sederhana kedalam bentuk hirarki[9]. Metode ini 
e-ISSN: 2685-7006 | p-ISSN: $2252-9063$

Kumpulan Artikel Mahasiswa Pendidikan Teknik Informatika

(KARMAPATI)

KดRMดPดTI

menggunakan matrik perbandingan berpasangan dengan nilai berdasarkan penilaian seorang pakar yang mengacu pada tabel intensitas kepentingan dari AHP[10]. Metode AHP memiliki beberapa langkah - langkah dalam proses perhitungannya yaitu sebagai berikut.

1. Menyusun Hirarki

Menyusun hirarki dimulai dengan menetapkan tujuan atau hasil yang ingin dicapai, sehingga tujuan berada pada posisi paling atas dalam struktur hirarki, kemudian dilanjutkan dengan kriteria yang digunakan, dan sampai paling bawah adalah alternatif, struktur hirarki dapat dilihat pada gambar dibawah ini.

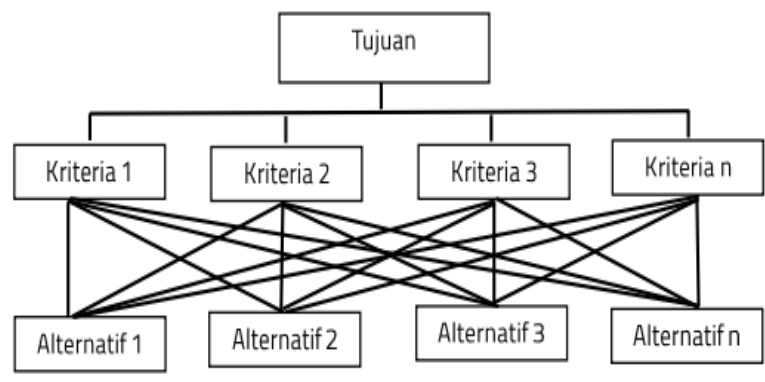

Gambar 1. Struktur Hirarki

2. Menentukan Prioritas Elemen

Penentuan prioritas elemen dilakukan oleh seorang ahli atau expert dalam bidang atau permasalahan yang akan diambil keputusannya. Menurut Saaty (1998), skala 1 sampai 9 merupakan skala terbaik untuk mengekpresikan pendapat. Dalam penentuannya harus berdasarkan tabel intensitas kepentingan yang dimiliki oleh AHP seperti dibawah ini.

Tabel 1. Nilai Intensitas Kepentingan

\begin{tabular}{|c|l|}
\hline $\begin{array}{c}\text { Intensitas } \\
\text { Kepentingan }\end{array}$ & \multicolumn{1}{|c|}{ Keterangan } \\
\hline 1 & Kedua elemen sama pentingnya \\
\hline 3 & $\begin{array}{l}\text { Elemen yang satu sedikit lebih } \\
\text { penting daripada elemen yang lain }\end{array}$ \\
\hline 5 & $\begin{array}{l}\text { Elemen yang satu lebih penting } \\
\text { daripada yang lainnya }\end{array}$ \\
\hline 7 & $\begin{array}{l}\text { Satu elemen jelas lebih mutlak } \\
\text { penting daripada elemen lainnya }\end{array}$ \\
\hline 9 & $\begin{array}{l}\text { Satu elemen mutlak penting } \\
\text { daripada elemen lainnya }\end{array}$ \\
\hline $2,4,6,8$ & $\begin{array}{l}\text { Nilai-nilai antara dua nilai } \\
\text { pertimbangan pertimbangan yang } \\
\text { berdekatan }\end{array}$ \\
\hline
\end{tabular}

3. Membuat Matrik Perbandingan Berpasangan
Volume 10, Nomor 3,Tahun 2021

Matrik perbandingan berpasangan merupakan konsep dasar yang digunakan dalam metode AHP dalam meghasilkan bobot relatif antar kriteria maupun alternatif[11]. Pembobotan dilakukan dengan cara membandingkan sepasang entitas. Hubungan antara entitas yang dibandingkan kemudian diberikan nilai bobot berdasarkan hasil penentuan prioritas elemen yang dilakukan sebelumnya. Dalam membuat matrik perbandingan berpasangan kita hanya perlu menentukan matrik segitiga atas saja, karena untuk matrik segitiga bawah nilainya merupakan kebalikan dari nilai matrik segitiga atas. Selain itu untuk nilai diagonal matrik bernilai satu, karena untuk bagian diagonal setiap entitas dengan dirinya sendiri. Matrik perbandingan berpasangan dapat dilihat seperti dibawah ini.

Tabel 2. Contoh Matriks Perbandingan Berpasangan

\begin{tabular}{|c|c|c|c|c|}
\hline & Kriteria-1 & Kriteria-2 & Kriteria-3 & Kriteria-n \\
\hline Kriteria-1 & K11 & K12 & K13 & K1n \\
\hline Kriteria-2 & K21 & K22 & K23 & K2n \\
\hline Kriteria-3 & K31 & K32 & K33 & K3n \\
\hline Kriteria-m & Km1 & Km & Km & Kmn \\
\hline
\end{tabular}

4. Sintesis

Sintesis adalah pertimbangan terhadap perbandingan berpasangan untuk mendapatkan keseluruhan nilai prioritas. Sintesis dilakukan dengan menjumlahkan nilai setiap kolom pada matrik perbandingan berpasangan, kemudian membagi nilai setiap kolom dengan hasil penjumlahan kolom yang bersangkutan untuk mendapatkan nilai normalisasi matrik. Kemudian terakhir dilakukan penjumlahan nilai dari setiap baris dan membaginya dengan jumlah elemen untuk mendapatkan nilai prioritas.

5. Mencari Nilai $\lambda$ Maksimum

Nilai $\lambda$ Maksimum merupakan nilai eigen terbesar dari matrik berordo $n$. Nilai $\lambda$ maksimum digunakan untuk mencari nilai konsistensi indeks dalam metode AHP.

6. Menghitung Konsistensi Indeks (CI)

Pengukuran konsistensi rasio dalam metode AHP, memerlukan nilai dari konsistensi indeks. Perhitungan konsistensi indeks dilakukan dengan rumus berikut ini.

$\mathrm{CI}=(\lambda$ maks $-\mathrm{n}) / \mathrm{n}-1$

$\mathrm{CI}=$ Konsistensi Indeks

$\lambda$ maks = Eigen Value Maksimum 
$\mathrm{n}=$ Jumlah Elemen

7. Menghitung Konsistensi Rasio (CR)

Menghitung konsistensi rasio diperlukan untuk mengetahui seberapa konsisten keputusan yang dihasilkan. Jika hasil perhitungan $\mathrm{CR}<0.1$ maka konsisten, jika $\mathrm{CR}=0.1$ maka cukup konsisten, dan jika $\mathrm{CR}>0.1$ maka sangat tidak konsisten. Konsistensi rasio bisa dihitung menggunakan rumus sebagai berikut.

$$
\begin{aligned}
& \mathrm{CR}=\mathrm{CI} / \mathrm{IRn} \\
& \mathrm{CR}=\text { Konsistensi Rasio } \\
& \mathrm{CI}=\text { Konsistensi Indeks } \\
& \mathrm{IR}=\text { Indeks Random } \\
& \mathrm{n}=\text { Jumlah Elemen }
\end{aligned}
$$

Rumus untuk mencari konsistensi rasio diatas memerlukan nilai dari Indeks Random (IR). Nilai IR yang digunakan untuk mencari konsistensi rasio dalam penelitian ini meliputi nilai indeks random dari beberapa peneliti yaitu Saaty, Noble, Oak Ridge, Golden Wang, Tumala Wan, Aguaron, dan Alonso Lamata[4]. Nilai untuk setiap indeks random tersebut dapat dilihat dibawah ini.

Tabel 3. Nilai Indeks Random

\begin{tabular}{|c|c|c|c|c|c|c|c|}
\hline Matriks & Saaty & Noble & Aguaron & $\begin{array}{c}\text { Alonso, } \\
\text { Lamata }\end{array}$ & $\begin{array}{c}\text { Oak } \\
\text { Ridge }\end{array}$ & $\begin{array}{c}\text { Golden } \\
\text { Wang }\end{array}$ & $\begin{array}{c}\text { Tumala, } \\
\text { Wan }\end{array}$ \\
\hline 1 & 0.00 & 0.00 & 0.00 & 0.00 & 0.00 & 0.00 & 0.00 \\
\hline 2 & 0.00 & 0.00 & 0.00 & 0.00 & 0.00 & 0.00 & 0.00 \\
\hline 3 & 0.58 & 0.49 & 0.525 & 0.5245 & 0.382 & 0.5799 & 0.500 \\
\hline 4 & 0.90 & 0.82 & 0.882 & 0.8815 & 0.946 & 0.8921 & 0.834 \\
\hline 5 & 1.12 & 1.03 & 1.115 & 1.1086 & 1.220 & 1.1159 & 1.046 \\
\hline 6 & 1.24 & 1.16 & 1.252 & 1.2479 & 1.032 & 1.2358 & 1.178 \\
\hline 7 & 1.32 & 1.25 & 1.341 & 1.3417 & 1.468 & 1.3322 & 1.267 \\
\hline 8 & 1.41 & 1.31 & 1.404 & 1.4056 & 1.402 & 1.3952 & 1.326 \\
\hline 9 & 1.45 & 1.36 & 1.452 & 1.4499 & 1.350 & 1.4537 & 1.369 \\
\hline 10 & 1.49 & 1.39 & 1.484 & 1.4854 & 1.464 & 1.4882 & 1.406 \\
\hline 11 & 1.51 & 1.42 & 1.513 & 1.5141 & 1.576 & 1.5117 & 1.433 \\
\hline 12 & 1.48 & 1.44 & 1.535 & 1.5365 & 1.476 & 1.5356 & 1.456 \\
\hline 13 & 1.56 & 1.46 & 1.555 & 1.5551 & 1.564 & 1.5571 & 1.474 \\
\hline 14 & 1.57 & 1.48 & 1.570 & 1.5713 & 1.568 & 1.5714 & 1.491 \\
\hline 15 & 1.59 & 1.49 & 1.583 & 1.5838 & 1.586 & 1.5831 & 1.501 \\
\hline
\end{tabular}

\section{METODELOGI PENELITIAN}

\section{A. Metode Pengumpulan Data}

Metode pengumpulan data yang digunakan dalam penelitian ini yaitu metode wawancara. Wawancara adalah pertemuan dua orang untuk bertukar infromasi dengan cara tanya jawab untuk mendapatkan makna dari suatu topik[12]. Pada penelitian ini wawancara dilakukan dengan bagian Waka 1 dan bagian kaprodi STMIK Primakara. Wawancara dilakukan secara tidak terstruktur, dengan tujuan untuk mendapatkan data atau informasi yang dapat digunakan dalam penelitian ini. Wawancara dilakukan dengan waka 1 untuk mendapatkan informasi dan data mengenai peraturan dan syarat dalam penilaian dosen terbaik, serta mendapatkan data mengenai nilai dosen, sedangkan untuk bagian kaprodi dilakukan untuk mendapatkan informasi pendukung mengenai penilaian dosen terbaik seperti alur dan mekanisme penilaian sebelumnya yang sudah dilakukan. Sedangkan untuk Instrumen penelitian berupa daftar pertanyaan yang terkait dengan penelitian ini dan juga perekam suara yang dapat membantu dalam mereka wawancara dengan narasumber.

\section{B. Jenis Data}

Jenis data yang digunakan dalam penelitian ini yaitu data primer dan data sekunder. Data primer merupakan data utama yang digunakan dalam penelitian ini[12]. Data primer dalam penelitian ini meliputi dokumen mengenai peraturan atau syarat yang digunakan dalam menentukan atau penilaian terhadap dosen terbaik, dalam dokumen ini berisikan data data yang terkait dengan kriteria penilaian, kemudian bobot awal dari setiap kriteria yang digunakan. Selain itu juga ada data mengenai alternatif yang dalam kasus ini berupa data mengenai nilai dosen untuk setiap kriteria yang ada, yang nantinya akan digunakan dalam perhitungan. Sedangkan data sekunder merupakan data pendukung dari data primer[12]. Dalam penelitian data sekunder berupa data yang diperoleh dari hasil studi literatur tentang teori terkait dengan penelitian ini. Data tersebut berupa jurnal - jurnal atau penelitian sebelumnya, maupun sumber informasi lain yang terkait dengan penelitian ini yang dapat membantu penelitian ini. 
e-ISSN: 2685-7006 | p-ISSN: $2252-9063$

Kumpulan Artikel Mahasiswa Pendidikan Teknik Informatika

(KARMAPATI)

KคRMAPคTI

C. Alur Penelitian

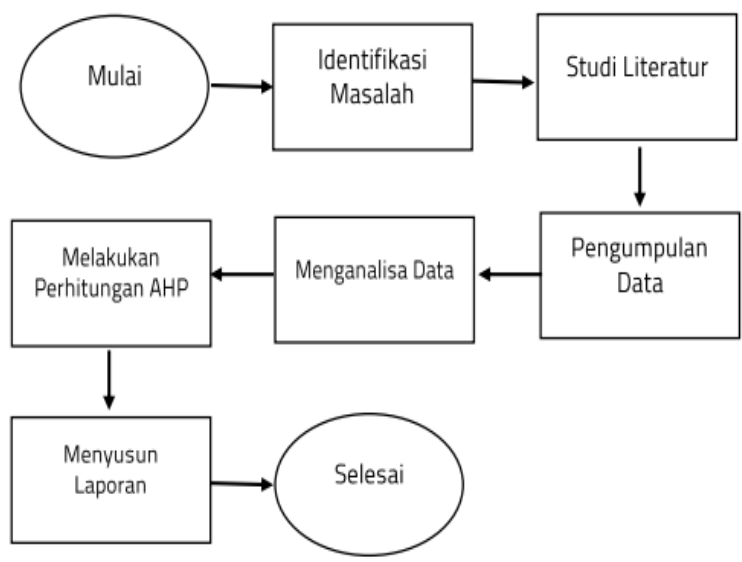

Gambar 2. Alur Penelitian

1. Penelitian dimulai dengan mengidentifikasi permasalahan yang ada.

2. Selanjutnya melakukan studi literaur untuk mendapatkan informasi dan teori terkait dengan permasalahan dari penelitian yang akan dilakukan

3. Tahapan berikutnya melakukan pengumpulan data untuk mendapatkan data apa saja yang akan digunakan dalam penelitian ini.

4. Berikutnya menganalisa data yang sudah dikumpulkan sebelumnya untuk bisa menyusun hirarki dan melakukan perhitungan menggunakan metode AHP.

5. Melakukan perhitungan dengan data yang yang sudah dianalisa dan disusun kedalam struktur hirarki menggunakan langkah perhitungan dari metode AHP.

6. Terakhir menyusun laporan dari hasil penelitian yang sudah dilakukan.

\section{HASIL DAN PEMBAHASAN}

Berdasarkan hasil pengumpulan data yang dilakukan pada bagian waka satu dan kaprodi STMIK Primakara, dalam penilaian kinerja dosen atau penentuan dosen terbaik, penentuan kriteria yang akan digunakan dalam penelitian ini didapatkan dari dokumen penilaian kinerja dosen yang didapatkan dari hasil wawancara dengan bagian waka 1 STMIK Primakara, sesuai dengan dokumen penilaian tersebut ada empat kriteria penilaian yang digunakan dalam menentukan dosen terbaik, kriteria tersebut meliputi Pendidikan, Penelitian, Pengabdian Masyarakat dan Kegiatan Penunjang. Kemudian Berdasarkan dokumen atau rubrik penilaian kinerja dosen didapatkan bobot awal untuk masing masing kriteria yaitu Pendidikan 40\%, Penelitian 25\%, Pengabdian Masyarakat 25\%, dan Penunjang 10\%. Selain itu untuk setiap kriteria memiliki rentang yang menunjukkan tingkat nilai yang didapatkan oleh setiap dosen yaitu Sangat Baik, Baik, Cukup dan Kurang.

\section{Menyusun Struktur Hirarki}

Tahapan pertama dalam perhitungan metode AHP yaitu menyusun herarki. Berdasarkan data yang didapatkan maka struktur hirarki dari kasus ini dimulai paling atas dengan tujuan yaitu dosen terbaik, diikuti dibawahnya oleh kriteria yaitu Pendidikan, Penelitian, Pengabdian Masyarakat, dan Kegiatan Penunjang. Posisi terbawah yaitu alternatif.

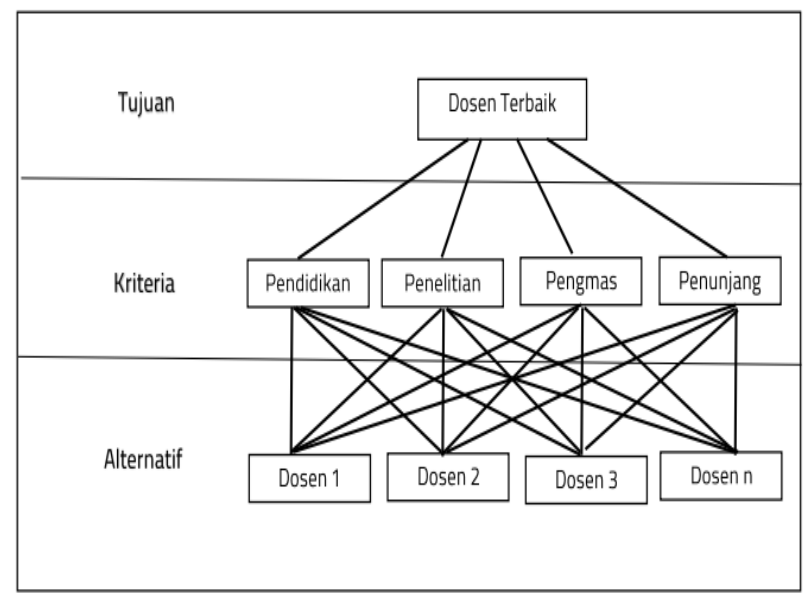

Gambar 3. Struktur Hirarki Dosen Terbaik

\section{Menghitung Bagian Kriteria}

Tahapan berikutnya melakukan perhitungan untuk bagian kriteria, dengan kriteria berupa Pendidikan, Penelitian, Pengabdian Masyarakat, dan Kegiatan Penunjang. sesuai dengan bobot awal setiap kriteria yaitu Pendidikan 40\%, Penelitian 25\%, Pengabdian Masyarakat 25\%, dan kegiatan Penunjang $10 \%$. Sedangkan untuk pemberian bobot tingkat kepentingan kriteria yang akan digunakan dalam menghitung bagian kriteria dengan metode AHP didapatkan dengan cara melakukan penyesuaian tingkat kepentingan untuk masing masing kriteria dengan bobot awal dari dokumen penilaian kinerja dosen, maka setelah dilakukan penentuan untuk tingkat kepentingan dari setiap kriteria didapatkan nilai dan matrik perbandingan berpasangan seperti berikut ini.

a. Membuat Matrik Perbandingan Berpasangan Bagian Kriteria.

Tabel 4. Matrik Perbandingan Berpasangan Kriteria

\begin{tabular}{|c|c|c|c|c|}
\hline & $\mathrm{K} 1$ & $\mathrm{~K} 2$ & $\mathrm{~K} 3$ & $\mathrm{~K} 4$ \\
\hline $\mathrm{K} 1$ & 1 & 3 & 3 & 5 \\
\hline $\mathrm{K} 2$ & 0.333 & 1 & 1 & 3 \\
\hline $\mathrm{K} 3$ & 0.333 & 1 & 1 & 3 \\
\hline Jumlah & 0.2 & 0.333 & 0.333 & 1 \\
\hline
\end{tabular}

Hasil pada matrik perbandingan berpasangan kriteria diatas diperoleh dengan membandingkan setiap elemen atau kriteria berdasarkan tingkat kepentingan setiap kriteria. seperti pada 
e-ISSN: 2685-7006 | p-ISSN: $2252-9063$

Kumpulan Artikel Mahasiswa Pendidikan Teknik Informatika

(KARMAPATI)

Volume 10, Nomor 3,Tahun 2021

\section{KARMAPATI}

tabel 4.1 posisi diagonal matrik diberikan nilai satu, karena membandingkan dengan dirinya sendiri. Kemudian untuk perbandingan pendidikan dengan penelitian, pada baris pendidikan dengan kolom penelitian diberikaan nilai 3, karena pendidikan dianggap sedikit lebih penting daripada penelitian. Sedangkan untuk baris penelitian dengan kolom pendidikan diberikan nila $1 / 3$ atau 0.3 , karena merupakan nilai kebalikan dari baris pendidikan dengan kolom penelitian. Begitu juga untuk seterusnya untuk baris dan kolom yang lain. Apabila sudah semua baris dan kolom diisi, maka dilakukan penjumlahan untuk setiap kolom, seperti contoh kolom satu dilakukan penjumlahan yaitu $1+0.333+0.333+0.2$ maka didapatkan jumlah untuk kolom satu senilai 1.867. begitu juga seterusnya untuk kolom dua sampai kolom empat.

b. Melakukan Sintesis terhadap Matrik Perbandingan Berpasangan kriteria

\section{Tabel 5. Matrik Normalisasi Kriteria}

Nilai pada tabel 4.2 Matrik Normalisasi Kriteria diatas diperoleh melalui hasil pembagian setiap elemen dengan hasil penjumlahan dari kolom bersangkutan pada matrik perbandingan berpasangan. Sebagai contoh nilai 0.536 pada baris satu kolom satu pada tabel 4.2 Matrik Normalisasi Kriteria, diperoleh dengan membagi nilai pada tabel 4.1 Matrik Perbandingan Berpasangan Kriteria, yaitu pada baris satu kolom satu dengan nilai 1 dibagi dengan dengan hasil penjumlahan dari kolom satu dengan nilai 1.867. sehingga didapatkan nilai untuk matrik normalisasi pada baris satu kolom satu sebesar 0.536. Cara yang sama juga dilakukan untuk nilai - nilai pada baris dan kolom dari matrik normalisasi kriteria yang lain.

Setelah semua nilai dari matrik normalisasi didapatkan, maka dilanjutkan dengan mencari nilai jumlah untuk tabel 4.2 Matrik Normalisasi Kriteria dengan cara menjumlahkan semua nilai pada setiap baris matrik normalisasi kriteria. Sebagai contoh mencari jumlah pada baris satu yaitu dengan menjumlahkan $0.536+0.536+0.536+0.417$ maka didapatkan hasil sebesar 2.077. Begitu juga untuk nilai jumlah yang lain dilakukan dengan cara yang sama.

Mencari nilai prioritas pada tabel 4.2 Matrik Normalisasi Kriteria, dilakukan dengan cara membagi nilai jumlah dari matrik normalisasi kriteria dengan jumlah elemen atau kriteria yang digunakan. Sebagai contoh nilai prioritas pada baris satu didapatkan dari hasil pembagian 2.077/4. Karena jumlah kriteria yang digunakan dalam penelitian ini adalah empat, sehingga didapaatkan nilai prioritas untuk baris satu sebesar 0.519. Begitu juga untuk mendapatkan nilai prioritas yang lain, dilakukan dengan cara yang sama.

\footnotetext{
c. Mencari Nilai $\lambda$ Maksimum

Mencari nilai $\lambda$ maksimum diperoleh dengan mengalikan nilai jumlah dari masing - masing kolom
}

pada tabel 4.1 Matrik Perbandingan Berpasangan dengan nilai prioritas pada tabel 4.2 Matrik Normalisasi Kriteria, kemudian menambahkan hasil perkalian yang pertama dan seterusnya, seperti contoh berikut.

$$
\begin{aligned}
= & (1.867 \times 0.519)+(5.333 \times 0.2001)+(5.333 \times 0.2001) \\
& +(12 \times 0.079) \\
= & 4.059
\end{aligned}
$$

Sehingga dari hasil perhitungan diatas didapatkan nilai $\lambda$ maksimum untuk kriteria sebesar 4.059.

d. Mencari Nilai Konsistensi Indeks (CI)

Menghitung konsistensi indeks (CI) dilakukan sesuai dengan rumus konsistensi indeks yaitu

$$
\begin{aligned}
\mathrm{CI} & =(\lambda \text { maks }-\mathrm{n}) / \mathrm{n}-1 \\
& =(4.059-4) 4-1 \\
& =0.02
\end{aligned}
$$

\begin{tabular}{|c|c|c|c|c|c|c|}
\hline & K1 & K2 & K3 & K4 & Jumlah & Prioritas \\
\hline K1 & 0.536 & 0.563 & 0.563 & 0.417 & 2.077 & 0.519 \\
\hline K2 & 0.179 & 0.188 & 0.188 & 0.25 & 0.804 & 0.201 \\
\hline K3 & 0.179 & 0.188 & 0.188 & 0.25 & 0.804 & 0.201 \\
\hline K4 & 0.107 & 0.063 & 0.063 & 0.083 & 0.315 & 0.079 \\
\hline
\end{tabular}

Sehingga didapatkan nilai konsistensi indeks (CI) untuk bagian kriteria sebesar 0.02 .

\section{e. Mencari Nilai Konsistensi Rasio (CR)}

Perhitungan konsistensi rasio dilakukan dengan membagi nilai CI yang didapatkan sebelumnya dengan nilai indeks random sesuai dengan dimensi matrik atau jumlah kriteria yang digunakan. Karena dalam kasus ini menggunakan empat kriteria, maka nilai indeks random (IR) akan disesuaikan dengan nilai indeks random dari masing - masing peneliti yaitu nilai indeks random Saaty, Noble, Oak Ridge, Golden Wang, Tumala Wan, Aguaron, dan Alonso Lamata sesuai dengan jumlah kriteria yang digunakan yaitu sebanyak empat.

Sebagai contoh perhitungan konsistensi rasio menggunakan nilai indeks random dari Saaty, didapatkan hasil sebagai berikut ini.

$$
\begin{aligned}
\mathrm{CR} & =\mathrm{CI} / \mathrm{IRn} \\
& =0.02 / 0.90 \\
& =0.022
\end{aligned}
$$

Sehingga dari hasil perhitungan konsistensi rasio menggunakan nilai indeks random dari Saaty didapatkan hasil 0.022. Begitu juga dengan perhitungan konsistensi rasio dengan menggunakan nilai indeks random dari peneliti yang lain dilakukan dengan cara yang sama, namun nilai dari indeks random disesuaikan dengan nilai indeks random dari masing - masing peneliti. Sehingga didapatkan hasil konsistensi rasio 
e-ISSN: 2685-7006 | p-ISSN: $2252-9063$

Kumpulan Artikel Mahasiswa Pendidikan Teknik Informatika

(KARMAPATI)

KARMAPATI

berdasarkan nilai indeks random dari masing - masing peneliti sebagai berikut.

Tabel 6. Nilai CR Kriteria

\begin{tabular}{|l|c|}
\hline \multicolumn{1}{|c|}{ IR } & Nilai CR \\
\hline Saaty & 0.022 \\
\hline Noble & 0.024 \\
\hline Oak Ridge & 0.021 \\
\hline Golden Wang & 0.022 \\
\hline Tumala, Wan & 0.023 \\
\hline Aguaron et al & 0.022 \\
\hline Alonso, Lamata & 0.022 \\
\hline
\end{tabular}

Berdasarkan nilai konsistensi rasio dari hasil perhitungan menggunakan masing - masing nilai indeks random (IR) yang ada, semua menunjukkan nilai kurang dari 0.1 atau $10 \%$ maka dapat disimpulkan bahwa semua indeks random (IR) yang

\begin{tabular}{|c|c|c|c|c|c|c|c|}
\hline & A1 & A2 & A3 & A4 & A5 & Jumlah & Prioritas \\
\hline A1 & 0.111 & 0.111 & 0.111 & 0.111 & 0.111 & 0.556 & 0.111 \\
\hline A2 & 0.111 & 0.111 & 0.111 & 0.111 & 0.111 & 0.556 & 0.111 \\
\hline A3 & 0.111 & 0.111 & 0.111 & 0.111 & 0.111 & 0.556 & 0.111 \\
\hline A4 & 0.333 & 0.333 & 0.333 & 0.333 & 0.333 & 1.667 & 0.333 \\
\hline A5 & 0.333 & 0.333 & 0.333 & 0.333 & 0.333 & 1.667 & 0.333 \\
\hline
\end{tabular}

digunakan untuk mengecek konsistensi bagian kriteria dapat dikatakan konsisten.

\section{Menghitung Bagian Alternatif}

Langkah - langkah yang dilakukan dalam melakukan perhitungan dibagian alternatif, mirip dengan perhitungan bagian kriteria, namun untuk bagian alternatif akan dilakukan perbandingan sebanyak empat kali, karena untuk bagian alternatif akan dibandingkan sesuai dengan jumlah kriteria yaitu empat kriteria, sehingga nanti alternatif akan dibandingkan untuk setiap bagian Pendidikan, Penelitian, Pengabdian Masyarakat, dan Penunjang.

Berdasarkan hasil pengumpulan data yang sudah dilakukan, dalam penelitian ini digunakan lima data dosen sebagai alternatif yang akan dihitung dengan menggunakan langkah - langkah AHP, yaitu Dosen $\mathrm{A}(\mathrm{A} 1)$, Dosen $\mathrm{B}(\mathrm{A} 2)$, Dosen C(A3), Dosen D(A4), dan Dosen E(A5) dengan nilai untuk masing - masing dosen sebagai berikut.

Tabel 7. Nilai Dosen

\begin{tabular}{|l|c|c|c|c|c|}
\hline & A1 & A2 & A3 & A4 & A5 \\
\hline Pendidikan & B & B & B & SB & SB \\
\hline Penelitian & B & B & B & K & C \\
\hline Pengmas & B & B & C & K & K \\
\hline
\end{tabular}

Volume 10, Nomor 3,Tahun 2021

\begin{tabular}{|l|c|c|c|c|c|}
\hline Penunjang & SB & SB & SB & C & K \\
\hline
\end{tabular}

\section{a. Perbandingan Alternatif Bagian Pendidikan}

Seperti langkah - langkah perhitungan yang dilakukan untuk bagian kriteria, maka untuk perhitungan alternatif pada bagian pendidikan dimulai dengan membuat matrik perbandingan berpasangan, maka dengan langkah pembuatan matrik perbandingan berpasangan maka didapatkan hasil seperti tabel dibawah ini.

Tabel 8. Matrik Perbandingan Berpasangan Alternatif Bagian Pendidikan

\begin{tabular}{|c|c|c|c|c|c|}
\hline & A1 & A2 & A3 & A4 & A5 \\
\hline A1 & 1 & 1 & 1 & 0.333 & 0.333 \\
\hline A2 & 1 & 1 & 1 & 0.333 & 0.333 \\
\hline A3 & 1 & 1 & 1 & 0.333 & 0.333 \\
\hline A4 & 3 & 3 & 3 & 1 & 1 \\
\hline A5 & 3 & 3 & 3 & 1 & 1 \\
\hline Jumlah & 9 & 9 & 9 & 3 & 3 \\
\hline
\end{tabular}

Selanjutnya melakukan sintesis dengan cara normalisasi matrik perbandingan berpasangan alternatif dan mencari nilai jumlah maupun nilai prioritas untuk bagian alternatif pendidikan diperoleh dengan cara seperti pada bagian kriteria. maka didapatkan hasil sebagai berikut ini.

Tabel 9. Matrik Normalisasi Alternatif Bagian Pendidikan

Setelah mendapatkan nilai normalisasi dan prioritas, maka dilanjutkan dengan mencari nilai $\lambda$ maksimum dan juga nilai konsistensi indeks (CI). Dengan menggunakan cara seperti bagian kriteria namun disesuaikan dengan jumlah elemen yang digunakan. Karena untuk bagian alternatif menggunakan lima elemen, maka nilai $\mathrm{n}$ untuk bagian alternatif disesuaikan menjadi 5. Sehingga didapatkan hasil untuk nilai $\lambda$ maksimum dan konsistensi indeks (CI) sebagai berikut.

$\lambda$ maksimum $=5$

$$
\begin{aligned}
\mathrm{CI} & =(\lambda \text { maks }-\mathrm{n}) / \mathrm{n}-1 \\
& =(5-5) / 5-1 \\
& =0
\end{aligned}
$$

Selanjutnya mencari nilai Konsistensi Rasio (CR), cara untuk mendapatkan nilai $\mathrm{CR}$ sama seperti bagian kriteria namun perlu menyesuaikan nilai indeks random (IR) sesuai dengan dimensi matrik atau jumlah alternatif yang digunakan. Sehingga didapatkan hasil nilai konsistensi rasio untuk masing - masing indeks random yang ada sebagai beikut.

Tabel 10. Nilai CR Alternatif Bagian Pendidikan

\begin{tabular}{|c|c|}
\hline IR & Nilai CR \\
\hline Saaty & 0 \\
\hline
\end{tabular}


e-ISSN: 2685-7006 | p-ISSN: $2252-9063$

Kumpulan Artikel Mahasiswa Pendidikan Teknik Informatika

(KARMAPATI)

KคRMAPคTI

\begin{tabular}{|c|l|}
\hline Noble & 0 \\
\hline Oak Ridge & 0 \\
\hline Golden Wang & 0 \\
\hline Tumala, Wan & 0 \\
\hline Aguaron et al & 0 \\
\hline Alonso, Lamata & 0 \\
\hline
\end{tabular}

b. Perbandingan Alternatif Bagian Penelitian

Perbandingan alternatif untuk bagian Penelitian dilakukan sama seperti pendidikan, sehingga didapatkan hasil untuk matrik perbandingan berpasangan sebagai

\begin{tabular}{|c|c|c|c|c|c|c|c|}
\hline & A1 & A2 & A3 & A4 & A5 & Jumlah & Prioritas \\
\hline A1 & 0.366 & 0.366 & 0.391 & 0.333 & 0.333 & 1.79 & 0.358 \\
\hline A2 & 0.366 & 0.366 & 0.391 & 0.333 & 0.333 & 1.79 & 0.358 \\
\hline A3 & 0.122 & 0.122 & 0.13 & 0.2 & 0.2 & 0.774 & 0.155 \\
\hline A4 & 0.073 & 0.073 & 0.043 & 0.067 & 0.067 & 0.323 & 0.065 \\
\hline A5 & 0.073 & 0.073 & 0.043 & 0.067 & 0.067 & 0.323 & 0.065 \\
\hline
\end{tabular}

berikut.

Tabel 11. Matrik Perbandingan Berpasangan Alternatif Bagian Penelitian

\begin{tabular}{|c|c|c|c|c|c|}
\hline & A1 & A2 & A3 & A4 & A5 \\
\hline A1 & 1 & 1 & 1 & 5 & 3 \\
\hline A2 & 1 & 1 & 1 & 5 & 3 \\
\hline A3 & 1 & 1 & 1 & 5 & 3 \\
\hline A4 & 0.2 & 0.2 & 0.2 & 1 & 0.333 \\
\hline A5 & 0.333 & 0.333 & 0.333 & 3 & 1 \\
\hline Jumlah & 3.533 & 3.533 & 3.533 & 19 & 10.333 \\
\hline
\end{tabular}

Melakukan sintesis seperti cara yang sama seperti pada bagian perbandingan alternatif bagian pendidikan maka didapatkan hasil sebagai berikut.

Tabel 12. Matrik Normalisasi Alternatif Bagian Penelitian.

Mencari nilai $\lambda$ maksimum dan nilai Konsistensi indeks dengan cara yang sama seperti sebelumnya sehingga didapatkan hasilnya sebagai berikut.

$$
\begin{aligned}
& \lambda \text { maksimum }=5.052 \\
& \begin{aligned}
\mathrm{CI} & =(\lambda \text { maks }-\mathrm{n}) / \mathrm{n}-1 \\
& =(5.052-5) / 5-1 \\
& =0.013
\end{aligned}
\end{aligned}
$$

Selanjutnya mencari nilai konsistensi rasio, dengan cara yang sama seperti sebelumnya pada bagian pendidikan, sehingga didapatkan hasil sebagai berikut.

Tabel 13. Nilai CR Alternatif Bagian Penelitian
Volume 10, Nomor 3,Tahun 2021

\begin{tabular}{|c|c|}
\hline IR & Nilai CR \\
\hline Saaty & 0.012 \\
\hline Noble & 0.013 \\
\hline Oak Ridge & 0.011 \\
\hline Golden Wang & 0.012 \\
\hline Tumala, Wan & 0.013 \\
\hline Aguaron et al & 0.012 \\
\hline Alonso, Lamata & 0.012 \\
\hline
\end{tabular}

\begin{tabular}{|c|c|c|c|c|c|c|c|}
\hline & A1 & A2 & A3 & A4 & A5 & Jumlah & Prioritas \\
\hline A1 & 0.283 & 0.283 & 0.283 & 0.263 & 0.29 & 1.403 & 0.281 \\
\hline A2 & 0.283 & 0.283 & 0.283 & 0.263 & 0.29 & 1.403 & 0.281 \\
\hline A3 & 0.283 & 0.283 & 0.283 & 0.263 & 0.29 & 1.403 & 0.281 \\
\hline A4 & 0.057 & 0.057 & 0.057 & 0.053 & 0.032 & 0.255 & 0.051 \\
\hline A5 & 0.094 & 0.094 & 0.094 & 0.158 & 0.097 & 0.538 & 0.108 \\
\hline
\end{tabular}

c. Perbandingan Alternatif Bagian Pengabdian Masyarakat

Perbandingan alternatif untuk bagian Pengabdian Masyarakat dilakukan sama seperti pendidikan, dan penelitian sehingga didapatkan hasil untuk matrik perbandingan berpasangan sebagai berikut.

Tabel 14. Matrik Perbandingan Berpasangan Alternatif Bagian Pengabdian Masyarakat

\begin{tabular}{|c|c|c|c|c|c|}
\hline & A1 & A2 & A3 & A4 & A5 \\
\hline A1 & 1 & 1 & 3 & 5 & 5 \\
\hline A2 & 1 & 1 & 3 & 5 & 5 \\
\hline A3 & 0.333 & 0.333 & 1 & 3 & 3 \\
\hline A4 & 0.2 & 0.2 & 0.333 & 1 & 1 \\
\hline A5 & 0.2 & 0.2 & 0.333 & 1 & 1 \\
\hline Jumlah & 2.733 & 2.733 & 7.667 & 15 & 15 \\
\hline
\end{tabular}

Melakukan sintesis seperti cara yang sama seperti pada bagian perbandingan alternatif bagian pendidikan dan penelitian maka didapatkan hasil sebagai berikut.

Tabel 15. Matrik Normalisasi Alternatif Bagian Pengabdian Masyarakat

Mencari nilai $\lambda$ maksimum dan nilai Konsistensi indeks dengan cara yang sama seperti sebelumnya sehingga didapatkan hasilnya sebagai berikut

$\lambda$ maksimum $=5.083$

$\mathrm{CI}=(\lambda$ maks $-\mathrm{n}) / \mathrm{n}-1$ 
e-ISSN: 2685-7006 | p-ISSN: $2252-9063$

Kumpulan Artikel Mahasiswa Pendidikan Teknik Informatika

(KARMAPATI)

KARMAPATI

$=(5.083-5) / 5-1$

$=0.021$

Selanjutnya mencari nilai konsistensi rasio, dengan cara yang sama seperti sebelumnya pada bagian pendidikan dan penelitian, sehingga didapatkan hasil sebagai berikut.

Tabel 16. Nilai CR Alternatif Bagian Pengabdian Masyarakat.

\begin{tabular}{|c|c|}
\hline IR & Nilai CR \\
\hline Saaty & 0.019 \\
\hline Noble & 0.020 \\
\hline Oak Ridge & 0.017 \\
\hline Golden Wang & 0.019 \\
\hline Tumala, Wan & 0.020 \\
\hline Aguaron et al & 0.019 \\
\hline Alonso, Lamata & 0.019 \\
\hline
\end{tabular}

\section{d. Perbandingan Alternatif Bagian Penunjang}

Perbandingan alternatif untuk bagian Pengabdian Masyarakat dilakukan sama seperti pendidikan, dan penelitian sehingga didapatkan hasil untuk matrik perbandingan berpasangan sebagai berikut.

Tabel 17. Matrik Perbandingan Berpasangan Alternatif Bagian Penunjang

\begin{tabular}{|c|c|c|c|c|c|}
\hline & A1 & A2 & A3 & A4 & A5 \\
\hline A1 & 1 & 1 & 1 & 5 & 7 \\
\hline A2 & 1 & 1 & 1 & 5 & 7 \\
\hline A3 & 1 & 1 & 1 & 5 & 7 \\
\hline A4 & 0.2 & 0.2 & 0.2 & 1 & 3 \\
\hline A5 & 0.143 & 0.143 & 0.143 & 0.333 & 1 \\
\hline Jumlah & 3.343 & 3.343 & 3.343 & 16.333 & 25 \\
\hline
\end{tabular}

Melakukan sintesis seperti cara yang sama seperti pada bagian perbandingan alternatif bagian pendidikan, penelitian dan pengabdian masyarakat maka didapatkan hasil sebagai berikut.

Tabel 18. Matrik Normalisasi Alternatif Bagian Penunjang

Mencari nilai $\lambda$ maksimum dan nilai Konsistensi indeks dengan cara yang sama seperti sebelumnya sehingga didapatkan hasilnya sebagai berikut

$\lambda$ maksimum $=5.097$

$$
\begin{aligned}
\mathrm{CI} & =(\lambda \text { maks }-\mathrm{n}) / \mathrm{n}-1 \\
& =(5.097-5) / 5-1 \\
& =0.024
\end{aligned}
$$

Volume 10, Nomor 3,Tahun 2021

Selanjutnya mencari nilai konsistensi rasio, dengan cara yang sama seperti sebelumnya pada bagian pendidikan, penelitian dan pengabdian masyarakat, sehingga didapatkan hasil sebagai berikut.

Tabel 19. Nilai CR Alternatif Bagian Penunjang

\begin{tabular}{|c|c|}
\hline IR & Nilai CR \\
\hline Saaty & 0.022 \\
\hline Noble & 0.024 \\
\hline Oak Ridge & 0.020 \\
\hline Golden Wang & 0.022 \\
\hline
\end{tabular}

\begin{tabular}{|c|c|c|c|c|c|c|c|}
\hline & A1 & A2 & A3 & A4 & A5 & Jumlah & Prioritas \\
\hline A1 & 0.299 & 0.299 & 0.299 & 0.306 & 0.28 & 1.484 & 0.297 \\
\hline A2 & 0.299 & 0.299 & 0.299 & 0.306 & 0.28 & 1.484 & 0.297 \\
\hline A3 & 0.299 & 0.299 & 0.299 & 0.306 & 0.28 & 1.484 & 0.297 \\
\hline A4 & 0.06 & 0.06 & 0.06 & 0.061 & 0.12 & 0.361 & 0.072 \\
\hline A5 & 0.043 & 0.043 & 0.043 & 0.02 & 0.04 & 0.189 & 0.038 \\
\hline \multicolumn{6}{|c|}{ Tumala, Wan } & \multicolumn{5}{c|}{0.023} \\
\hline \multicolumn{6}{|c|}{ Aguaron et al } & \multicolumn{5}{c|}{0.022} \\
\hline
\end{tabular}

Berdasarkan semua hasil perbandingan dan hasil perhitungan nilai konsistensi rasio (CR) dengan menggunakan semua nilai indeks random (IR) yang ada, semua nilai konsistensi rasio dari masing - masing peneliti yaitu Saaty, Noble, Oak Ridge, Golden Wang, Tumala Wan, Aguaron, dan Alonso Lamata, untuk bagian kriteria maupun bagian alternatif, semua menunjukkan nilai dibawah 0.1 atau $10 \%$. Maka dengan begitu dapat dikatakan bahwa hasil perbandingan untuk bagian kriteria dan alternatif adalah konsisten dan bisa dilanjutkan ke tahap perangkingan.

\section{Perangkingan}

Perangkingan dilakukan dengan mengalikan nilai prioritas dari masing - masing dosen berdasarkan hasil perbandingan pada setiap kriteria dengan nilai prioritas dari setiap kriteria. Kemudian melakukan penjumlahan dari hasil perkalian tersebut untuk mendapatkan nilai total bagi masing - masing dosen. Sebagai contoh perhitungan nilai total Dosen A, maka didapatkan hasil sebagai berikut.

$$
\begin{aligned}
& =(0.519 \times 0.111)+(0.201 \times 0.281)+(0.201 \times 0.358)+ \\
& (0.079 \times 0.297) \\
& =0.209365
\end{aligned}
$$

Maka nilai total untuk Dosen A adalah 0.209365, begitu juga cara untuk mencari nilai total dari dosen yang lain. Sehingga nilai untuk dosen yang lain dan hasil perangkingan akhir dapat dilihat pada tabel dibawah ini. 
e-ISSN: 2685-7006 | p-ISSN: $2252-9063$

Kumpulan Artikel Mahasiswa Pendidikan Teknik Informatika

(KARMAPATI)

KคRMAPคTI

Tabel 20. Ranking

\begin{tabular}{|c|c|c|}
\hline Nama & Nilai & Ranking \\
\hline Dosen E & 0.210677 & 1 \\
\hline Dosen A & 0.209365 & 2 \\
\hline Dosen B & 0.209365 & 3 \\
\hline Dosen D & 0.202022 & 5 \\
\hline Dosen C & 0.168570 & 4 \\
\hline
\end{tabular}

Berdasarkan hasil perhitungan dan perangkingan yang sudah dilakukan maka pada tabel diatas, Dosen E memiliki nilai total tertinggi dengan nilai 0.210677 sebagai rangking pertama, diikuti oleh Dosen A dengan nilai 0.209365, dilanjutkan Dosen B dengan nilai 0.209365, lalu Dosen D dengan nilai total 0.202022, dan terakhir Dosen C dengan total nilai 0.168570. Dengan konsistensi rasio (CR) untuk setiap perbandingan kriteria dan alternatif yang masih dibawah 0.1 atau $10 \%$ yang berarti keputusan yang dihasilkan dengan perhitungan metode AHP dengan menggunakan nilai indeks random (IR) dari Saaty, Noble, Oak Ridge, Golden Wang, Tumala Wan, Aguaron, dan Alonso Lamata, semuanya konsisten. Maka berdasarkan hasil perhitungan diatas, metode analytical hierarchy process dapat menghasilkan keputusan mengenai dosen terbaik dengan konsistensi rasio yang didapatkan dari masing - masing nilai indeks random yang ada masih dibawah 0.1 atau konsisten.

\section{PENUTUP}

Setiap dosen berhak mendapatkan penghargaan atas kinerja dan prestasinya diperguruan tinggi, karena telah menjalankan tugasnya sebagai tenaga pendidik berdasarkan Tri Darma Perguruan Tinggi. Disisi lain perkembangan teknologi informasi terus berkembang, salah satu bentuk perkemangan teknologi informasi adalah adanya sistem pendukung keputusan. Sistem pendukung keputusan merupakan sistem yang terkomputerisasi yang membantu pengambil keputusan dalam menyelesaikan permasalahan yang melibatkan sebuah keputusan. Dalam sistem pendukung keputusan menggunakan metode dalam perhitungannya, salah satu metode sistem pendukung keputusan yaitu metode Analytical Hierarchy Process (AHP). Metode AHP memiliki tahapan untuk menghitung tingkat konsistensi keputusan yang dihasilkan dengan menghitung nilai Konsistensi Rasio (CR), dalam perhitungan konsistensi rasio menggunakan nilai Indeks Random (IR) untuk mendapatkan seberapa besar tingkat konsistensinya. Seiring perkembangan jaman nilai Indeks Random mulai diteliti oleh beberapa peneliti antara lain Saaty sebagai penemu metode AHP, kemudian Noble, Oak Ridge, Golden Wang, Tumala Wan, Aguaron, dan Alonso Lamata.

Berdasarkan hasil penelitian yang dilakukan pada kampus STMIK Primakara mengenai penerapan metode AHP dalam menentukan dosen terbaik menggunakan nilai Indeks
Volume 10, Nomor 3,Tahun 2021

Random dari beberapa peneliti. Didapatkan hasil bahwa pada kampus STMIK Primakara menggunakan empat kriteria penilaian dalam menentukan dosen terbaik. Kriteria tersebut meliputi Pendidikan dengan bobot awal 40\%, Penelitian $25 \%$, Pengabdian Masyarakat 25\% dan Kegiatan Penunjang $10 \%$.

Setelah dilakukan perhitungan maka didapatkan hasil bahwa dengan menggunakan metode AHP menghasilkan nilai prioritas untuk setiap kriteria yaitu Pendidikan 0.519, Penelitian 0.201, Pengabdian Masyarakat 0.201 dan Penunjang 0.079. Dengan nilai hasil perbandingan untuk alternatif dan perangkingan didapatkan Dosen E memiliki nilai total tertinggi dengan nilai 0.210677 sebagai rangking pertama, diikuti oleh Dosen A dengan nilai 0.209365, dilanjutkan Dosen B dengan nilai 0.209365, lalu Dosen D dengan nilai total 0.202022, dan terakhir Dosen C dengan total nilai 0.168570. Dengan konsistensi rasio (CR) untuk setiap perbandingan kriteria dan alternatif yang masih dibawah 0.1 atau $10 \%$ yang berarti keputusan yang dihasilkan dengan perhitungan metode AHP dengan menggunakan nilai indeks random (IR) dari Saaty, Noble, Oak Ridge, Golden Wang, Tumala Wan, Aguaron, dan Alonso Lamata, semuanya konsisten.

\section{REFERENSI}

[1] K. Pendidikan, D. A. N. Kebudayaan, D. Pendidik, and D. A. N. Tenaga, "Pedoman umum pemilihan dosen berprestasi," 2014.

[2] P. S. Informatika, F. Teknik, and U. Muhammadiyah, "Perancangan sistem pendukung keputusan penentuan warga miskin dengan metodelogi ahp di kecamatan sepatan kabupaten tangerang," pp. 59-66.

[3] W. Setiyaningsih, Konsep Sistem Pendukung Keputusan. 2015.

[4] J. A. Alonso and M. T. Lamata, "Consistency in the analytic hierarchy process: A new approach," Int. J. Uncertainty, Fuzziness Knowlege-Based Syst., vol. 14, no. 4, pp. 445-459, 2006, doi: 10.1142/S0218488506004114.

[5] D. Setiyadi, "PENILAIAN KINERJA DOSEN DENGAN MENGGUNAKAN METODE ANALYTIC HIERARCHY PROCESS ( AHP ) PADA STIE AHMAD DAHLAN JAKARTA," vol. VII, no. 02, pp. 1-17, 2012.

[6] P. Hasan, E. Utami, and A. Nasiri, "Sistem Pendukung Keputusan Penilaian Kinerja Dosen Menggunakan Metode AHP di STIMIK," vol. 4, pp. 499-510, 2018.

[7] H. Budiarto, "SISTEM PENDUKUNG KEPUTUSAN PENILAIAN KINERJA DOSEN BERBASIS FUZZY - AHP PADA STMIK STIKOM BALI HARY BUDIARTO Dosen Tetap STMIK Eresha," vol. VIII, no. 01 , pp. 43-61.

[8] B. Firmansyah and A. M. Wihandar, "SISTEM PENDUKUNG KEPUTUSAN MONITORING \& EVALUASI KINERJA DOSEN PROGRAM STUDI 
KARMAPATI

INFORMATIKA FAKULTAS ILMU KOMPUTER IBI KOSGORO 1957 MENGGUNAKAN METODE ANALYTHIC HIERARCHY PROCESS ( AHP )," vol. 1, no. 2, pp. 127-142, 2020.

[9] V. N. Sari, M. W. Sari, and S. R. Mulyani, "Analisis Dan Usulan Solusi Sistem Untuk Mendukung Keputusan Penilaian Kinerja Dosen Menggunakan Metode Analytical Hierarchy Process ( AHP )," no. September, pp. 142-149, 2019.

[10] S. Rinaldi, T. Informatika, and K. Dosen, "IMPLEMENTASI METODE ANALYTICAL HIERARCHY PROCES S DAN SIMPLE ADDITIVE WEIGHTING UNTUK PEMILIHAN DOSEN TERBAIK STUDI KASUS DECISION SUPPORT
Volume 10, Nomor 3,Tahun 2021

SYSTEM TO CHOOSE THE BEST LECTURER PERFORMANCE WITH ANALYTICAL HIERARCHY PROCES S AND SIMPLE,” vol. 6, no. 6, pp. 655-664, 2019, doi: 10.25126/jtiik.201961636.

[11] P. A. Jusia, "Decision Support System for Supplier Selection using Analytical Hierarchy Process ( AHP ) Method," vol. 4, no. 2, 2017.

[12] T. Komunikasi, "yang muncul kemudian. Perkembangan teknologi media elektronik modern misalnya telah menyatukan individu dalam sebuah jaringan komunikasi yang lebih bersifat instan yang disebut," vol. 1, pp. 202-224, 2017. 